Accepted manuscript. Article accepted for publication in International Journal of Sustainable Agricultural Management and Informatics (IJSAMI) on 15 January 2019.

\title{
Identifying knowledge brokers, artefacts and channels for waste reduction in agri-food supply chains
}

\section{Huilan Chen *, Shaofeng Liu, Guoqing Zhao}

University of Plymouth,

Drake Circus, Plymouth, Devon, PL4 8AA, United Kingdom

Email: huilan.chen@plymouth.ac.uk

Email: shaofeng.liu@plymouth.ac.uk

Email: guoqing.zhao@plymouth.ac.uk

*Corresponding author

\section{Festus Oderanti}

University of Hertfordshire,

Room M233, deHavilland Campus, Hatfield, AL10 9AB, United Kingdom

Email: F.Oderanti@Herts.ac.uk

\section{Cécile Guyon}

Bretagne Développement Innovation,

1, bis route of Fougères, 35510 Cesson-Sévigné, France

Email: c.guyon@bdi.fr

\section{Biljana Mileva Boshkoska}

"Jožef Stefan" Institute, Faculty of Information Studies, Ljubljanska cesta 31a, 8000 Novo mesto, Slovenia

Email: biljana.mileva@fis.unm.si

\begin{abstract}
Knowledge mobilization has been proven crucial to increasing organization's efficiency, improving profitability and achieving competitive advantage. The paper aims to explore an approach to integrating knowledge mobilization within agri-food supply chains to enhance collaboration of all value chain actors and achieving a holistic reduction of waste. The research focus will be on the identification of knowledge brokers, artefacts and channels in order to facilitate knowledge mobilization crossing boundaries to reduce agri-food wastes. Cauliflower from Brittany, France's largest cauliflower production and export region, provides the data underlying the following analysis. Research methods includes semi-structured interview and documentation for data collection and thematic analysis for data analysis. This study has great potential in helping make the right supply chain decisions for eliminating lean wastes in agri-food industry.
\end{abstract}


Keywords: Knowledge Mobilization, Knowledge Brokers, Artefacts, Knowledge Channels, Muda (waste) Reduction, Agri-food Supply Chains

Biographical statement: Huilan Chen is a $\mathrm{PhD}$ student of Business Management in the University of Plymouth. Most of her research has focused on knowledge management programs and their impact on lean supply chain performance. Her main fields of research interest are situated in the domain of agri-food supply chain management. 


\section{INTRODUCTION}

Over the last decade, knowledge has become the engine of economic development. For the agricultural sector, knowledge management is used to develop new technologies to improve the quantity and quality of products it can produce. In rural areas, the economic welfare of households depends on the decisions they make about the use of experience, information and knowledge. Therefore, knowledge management is also vital for increasing the growth of the agriculture sector (Semeon et al., 2013). Knowledge management in agri-food supply chains emphasizes collaboration since knowledge is created collectively in groups through mechanisms of networking and communication (Hartwich et al., 2007).

Lean manufacturing, a quality management approach initially developed to eliminate waste in Japanese corporation, Toyota, in the late 20s century, is defined as 'a system that utilizes fewer inputs and creates the same outputs while contributing more value to customers' (Womack et al., 1990). After decades of development, lean has expanded to further theories and was summarized into lean thinking that requires collaboration of all value chain actors with a common goal to boost customer satisfaction (Womack and Jones, 1997). Nowadays, its application is not only limited to the automobile sector, but also in other sectors particularly the agri-food industry (Dora et al., 2014).

However, the fragmented nature of agri-food supply chains as a critical challenge is hindering knowledge production which leads to low levels of productivity (Anastasiadis and Poole, 2015). Thus, knowledge-based solutions such as lean has been proposed to overcome the problem of the negative impact of fragmentation. The lean principles are to increase the quality of products, increase value by eliminating waste and increase flow through the process. Knowledge mobilization differs in terms of what knowledge is to be transferred and how it is to be communicated. The process of knowledge mobilization requires more shared interaction between decision-makers and experts. Given the fragmentation of agri-food supply chains, chain actors have few understandings about an issue (e.g. waste reduction), however they consequently can gain a complete comprehension by interactively aligning their mental models through knowledge mobilization. This means that when knowledge is shared between experts and decision makers, they create context-specific knowledge that can be used to create fresh perspectives or acquire new skills (Chen et al., 2017). From all above, knowledge mobilization and lean have a positive influence on agri-food supply chains.

This study attempts to investigate what knowledge mobilization strategies can reduce waste in agri-food supply chains. Therefore, the identification of knowledge brokers, artefacts and channels to formulate knowledge mobilization strategies and the identification of lean wastes in agri-food supply chains have been emphasized in this study.

The paper is organized as follows. After this introduction, the second part discusses literature on knowledge mobilization and lean supply chain decisions in agri-food sector. Through literature review, a theoretical framework has been developed in part three. The fourth part is the research methodology for collecting empirical evidence, and the fifth part is the case study in the Brittany cauliflower supply chain, followed by part six on conclusions.

\section{LITERATURE REVIEW}

\subsection{Knowledge mobilization}

Theoretical underpinnings of knowledge mobilization can be understood in terms of three primary perspectives: information-processing, cultural and political perspectives (Carlile, 2002; Carlile, 2004; Kellogg et al., 2006). Linear, one-way approach to knowledge 
mobilization has proven problematic in practice, therefore, it has been complemented by a number of models and frameworks, which also take into consideration cultural and political factors that shape the interactions among chain actors. These emphasize the bidirectional nature of knowledge mobilization, and the importance of contextual factors and the need for active engagement, interaction and collaboration in managing knowledge mobilization (Carlile, 2004). Knowledge boundary has been recognized as discontinuities that highlights the nature of cultural and political restrictions, and collaborations has been identified as the solution to successfully bridge any boundaries and fulfil the goal of knowledge mobilization (Kellogg et al., 2006). Boundaries can be defined as sociocultural differences between practices that can lead to discontinuity in action or interaction. This understanding of boundaries partially overlaps with the notion of gaps popular in the knowledge mobilization literature, where gaps are seen as the network holes, spaces and missing ties that create between group problems and opportunities for their resolution. The barriers to knowledge sharing crossing boundaries can be classified as syntactic (difference in language), semantic (difference in meaning) and pragmatic (difference in practice) (Carlile, 2002; Carlile, 2004; Kellogg et al., 2006). Three types of bridges can be identified from literature to cross these knowledge boundaries. Boundary spanners: middlemen, intermediaries or agents who act as negotiators, interpreters, messengers or commissioners between different merchants or individuals. Boundary spanners can exist in individuals, organizations and structures. Early examples of it include an informal network that connected to agriculture sector to 'county agent' in order to disseminate innovations to farmers in the USA (Rogers, 2003). Later, consultancy has been considered as a delegate for boundary spanners (Jacobson et al. 2005). Until relatively recently, in agri-food contexts, the boundary spanner is often performed by organizations with professional roles, that is, the agricultural development agents (extension workers). Support groups act as brokers between the available knowledge and the individual needs of farming households. It is well known that the success of the implementation of new agricultural technology depends on the success of communication between the agricultural experts and the farmers (Islam, 2010). Boundary objects: artefacts possessing interpretative flexibility that allows them to overcome syntactic, semantic and pragmatic boundaries, hence contribute to knowledge mobilization (Kislov et al, 2011). For example, the knowledge processed are normally stored in knowledge artefacts pertaining to technology, laws or regulations, and so on (Semeon et al, 2013). Boundary interactions: at the supply chain level, the way to identify, interact and exploit the value chain has been shown to overcome knowledge boundaries (Mason and Leek, 2008). Knowledge mobilization (vertically and horizontally) within organizations appears to be affected by knowledge communication mechanisms (e.g. ICT, conferences, training and community of practice) (Kislov et al, 2011). Mason and Leek (2008) uncovered that the categories of 'hard' and 'soft' knowledge communication mechanisms can drive improvement to dynamic business models across supply chain networks.

\subsection{Knowledge brokers, artefacts and channels}

Despite several studies in the area of knowledge mobilization, the clear evidence surrounding this issue is relatively weak, especially the knowledge brokering theory and knowledge artefacts strategy. In addition, related work to knowledge mobilization was mainly conducted in the health sector, but there is a lack of empirical study focusing on agri-food supply chains. Moreover, knowledge communication mechanisms are not systematically described, so knowledge channels remain intangible. This has caused poor coordination of the 
collective knowledge among supply chain actors to enhance decision support systems (Ali et al, 2016).

From the literature, the role of brokers has been emphasized in the knowledge mobilization filed is to make research and practice more accessible to each other. Therefore, knowledge brokers can be defined as people or organizations that move knowledge around and create connections between researchers and their various audiences (Meyer, 2010). Recently, three distinct categories of knowledge brokers have been developed. First, to know how to create, acquire, diffuse and use knowledge requires knowledge which is embodied in the brokers. In order to manage these activities, the brokers here are seen as knowledge managers. Second, brokering focuses on the interface between the "producers" and "users" of knowledge, in this context, brokers are been as linkage agents. Third, to enhance access to knowledge within a society by providing training to knowledge users, brokers are seen as capacity builders (Ward, House and Hamer, 2009). Given that the roles of the knowledge producers (experts) and the knowledge users (decision makers) are concrete, there is a need to apply a set of knowledge brokerage tools for improving the interaction between experts and decision makers. Offering a structured approach towards impact assessment, it allows framing the context, organization, scheduling and method selection in the light of knowledge brokerage objectives (Bournaris et al., 2016). Above all, brokers have to create a common language, being a sort of linguistic creator, whose task is constructing a language in which the parties can place themselves and engage with each other in mutual understanding.

Given the benefits of artefacts in knowledge mobilization field, it has been paid more and more attention nowadays. According to Mariano and Awazu (2016), through the use of artefacts, knowledge could be better organized and performed in organizational contexts. Therefore, when implementing a knowledge mobilization process, decision-maker and experts would be aware of the role of artefacts and their related benefits. There are several manifestations on artefacts in the knowledge mobilization (Mariano and Awazu, 2016). For instance, artefacts are defined as sketches and diagrams (Holford, 2016); intranet applications, enterprise resource planning system, repositories and quality management systems (Hustad, 2007); referrals, laboratory reports and instructions, as well as routines and rules, standards, drawings and documentations (Maaninen-Olsson et al., 2008); co-created assessment tools (Kajamaa, 2011) and principles and methods for evaluation (Zuo and Panda, 2013).

Knowledge communication mechanisms (knowledge channels) play an integral role in knowledge mobilization process. Two different types of knowledge communication mechanisms are identified: hard and soft. Hard mechanism can be understood as an institutionalized way to mobilize knowledge by written documents that may be available in paper or in electronic format. Research on hard mechanism to knowledge mobilization has examined issues such as explicit knowledge can be mobilized more easily through many formal channels for gaining attention in supply chains (Hansen and Hass, 2001). Hutchinson and Quintas (2008) indicated that formal channel concerns policies, plans, structures and initiatives that are named and governed by the concept of knowledge mobilization. In contrast, soft mechanisms promote the social production of new knowledge that allows chain actors to adapt and apply their learning about specific skill sets in their own specific cultural and institutional contexts. Research on tacit knowledge has emphasized the role of soft mechanisms in facilitating knowledge mobilization (Taminiau et al., 2009). Moreover, it seems difficult to divorce from these two knowledge communication mechanisms and they are both found to be applied in the knowledge mobilization literature. 


\subsection{Lean in agri-food supply chains}

Lean penetration into agriculture sector is slow due to the perishability of a wide range of food products, complexity of the food supply chain and consumers' dynamic preferences (Dora et al., 2016). Cox and Chicksand (2008) argued that there is a clear need to understand the specific characteristics of the food supply chains, otherwise the lean manufacturing practices may not bring the expected result or be unfruitful. Three key characteristics of the food product market are identified: demand uncertainty, customer order lead time, and supply chain lead time allowance. Demand uncertainty needs the development of product variety, updating packaging and improvement of product shelf life and so forth. The other two characteristics require high responsiveness by the supply chain management and greater supply chain flexibility. In terms of waste reduction, the flexibility requirements also support the same goal in perishable food supply chains (Kittipanya-ngam et al., 2010).

Scholars agree that one of the main principles of lean is waste reduction (e.g., Bhamu and Sangwan, 2014). Ohno (1988) divided wastes into seven categories. Shingo (1989) listed the same seven kinds of wastes identified in the Toyota Production System. More recently, the seven types of waste are further described by Liker (2003). Nowadays, lean in agri-food sector involves the same seven lean wastes, they are overproduction, defects, inventory, over processing, transport, motion, and waiting (De Steur et al., 2016). It is necessary to reduce waste at different sections of the chain in order to pursue efficient and effective supply chain performance. For example, in a study analyzing pork production supply chain, incorrect weights and fat levels at primary production were considered as defects (Taylor, 2005). As a lean waste, overproduction has appeared in food processing mainly due to misalignment of production with consumer demand for ready to eat foods (De Steur et al., 2016). However, there are few literatures related to lean penetration into the entire agri-food supply chain in order to achieve a holistic reduction of waste (Dora et al, 2014).

\section{THEORETICAL FRAMEWORK}

Based on the review of literature in Section 2, in order to explore a way to merge knowledge mobilization with lean decisions (e.g. waste reduction), a theoretical knowledge mobilization framework is proposed, as shown in Figure 1. On the left hand side of the framework, it is the integration of knowledge brokers, artefacts, and knowledge channels to support knowledge mobilization crossing boundaries. On the right hand side are the seven types of waste. The arrow from the left to right represents the impact of knowledge mobilization on waste reduction. 


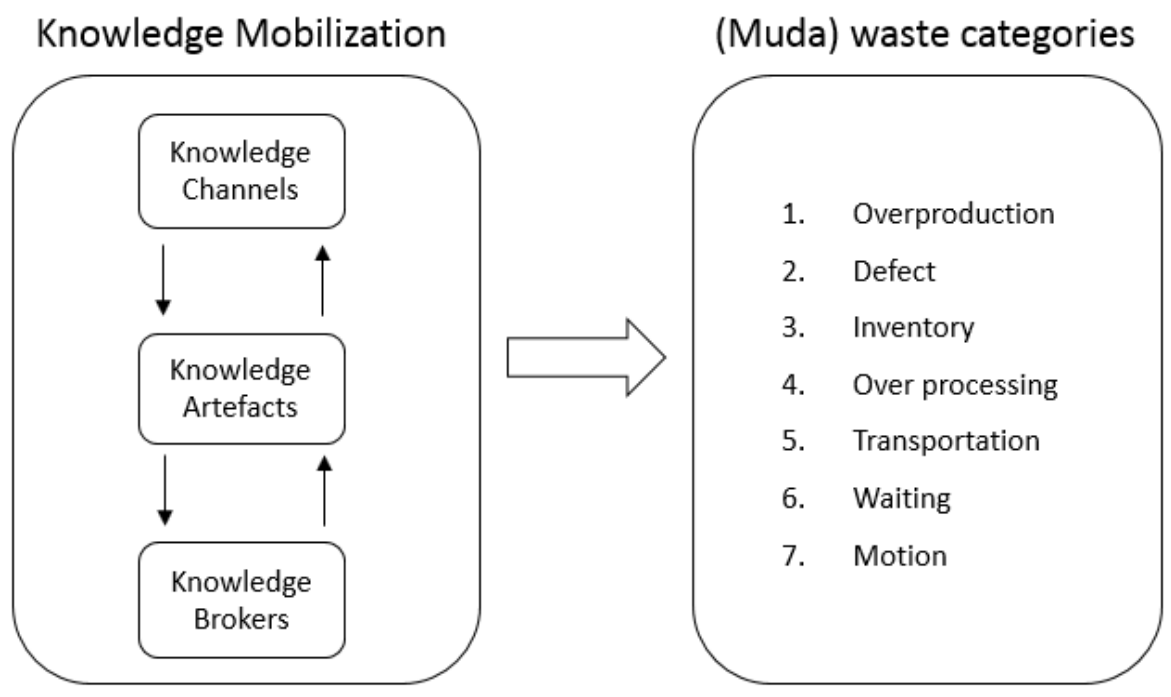

Figure 1: A knowledge mobilization framework

The seven types of wastes have been refined by Liu (2013) as a model used in supply chain management scope, which will be used as the foundation for this research but will be extended to agri-food supply chains:

1. Overproduction: producing too much or too soon required by the downstream operations in the supply chain.

2. Defect: products provided by suppliers/upstream operations have quality problems or poor delivery performance.

3. Inventory: surplus storage between up-stream and down-stream operations in the supply chain.

4. Over processing: non-value adding operations resulting from poor supply network design.

5. Transportation: moving products among supply chain actors unnecessarily.

6. Waiting: long lead-time for products from upstream operations/suppliers.

7. Motion: poor workplace organization resulting in poor ergonomics in the supply chain.

Finding waste is a difficult task and various knowledge mobilization tools are needed to analyze the physical product and information environment. Therefore, in terms of knowledge mobilization process, relevant agricultural supply chain knowledge should be captured from the knowledge sources. The knowledge processed should be stored in knowledge artefacts. At the same time, these knowledge need to be transferred to agricultural knowledge brokering by using suitable communication mechanisms. Knowledge then is applied by all chain actors for making lean decisions in various agricultural areas. The following section discusses the research methodology which supports empirical data collection and analysis to validate the theoretical framework.

\section{METHDOLOGY}

\subsection{Data collection approach}

According to Jasti and Kodali (2014), the most popular empirical research methodological approach in the field of lean is the case study. Moreover, the majority of the lean studies in the food sector is based on the case study approach in order to concentrate on lean manufacturing techniques (Dora et al, 2014). Case study approach has several advantages: it can more easily discover a research problem and find out a range of ideas about the problem. 
It can also help to understand different perspectives between groups of participants. Moreover, such an approach can answer what, why and how research questions necessary to make the study more in depth (Morse, 2003). Therefore, the case study approach has been used for this study. Two data collection tools are conducted including semi-structured individual interviews and documentation. Interview questions are derived from the review of relevant literature and the theoretical study adopted. The interview questions are pre-tested with academicians and practitioners to ensure all items are clearly understood with no ambiguity. According to Saunders et al. (2009), an individual interview is a conversation between two persons which is designed to elicit the interviewee's knowledge and perspective on knowledge mobilization and waste reduction in this study. Individual interviews are not only useful for exploring the interviewee's understandings, experiences and perspectives of an issue, but also allow the interviewer to ask into a complex issue, to learn more about the contextual factors that govern individual experiences. The authors also have access to company databases include the order data, point of sale data and delivery data and so forth to complete data collection process.

\subsection{Data analysis approach}

The thematic analysis was employed to analyze data collected through interviews in this study. Thematic analysis is one of the approaches in analyzing qualitative data; it concentrates on the themes and patterns, emphasizing, pinpointing, examining and recording patterns within the data (Braun and Clarke, 2006). Thematic analysis is normally concerned with experiences focused methodologies. According to King and Horrocks (2010), a number of themes are identified by the following three stages:

- Descriptive coding (first-order codes): the researcher identifies those parts of the transcript data that address the research questions and allocates descriptive codes throughout the whole transcript.

- Interpretative coding (second-order themes): the researcher groups together descriptive codes that seem to share some common meaning and create an interpretative code that captures this.

- Defining overarching themes (aggregate dimensions): the researcher identifies a number of overarching themes that characterize key concepts in the analysis.

In this study, the second-order themes were identified using first-order codes and they were categorized as aggregated dimensions to reveal knowledge brokers, artefacts and knowledge channels in order to enhance knowledge mobilization and achieve lean supply chains. Then to discover the main identified wastes and the solutions to reduce the wastes. Each interview transcript was read by several times and coded on the basis of terms or phrases used by participants (See Figure 2). 


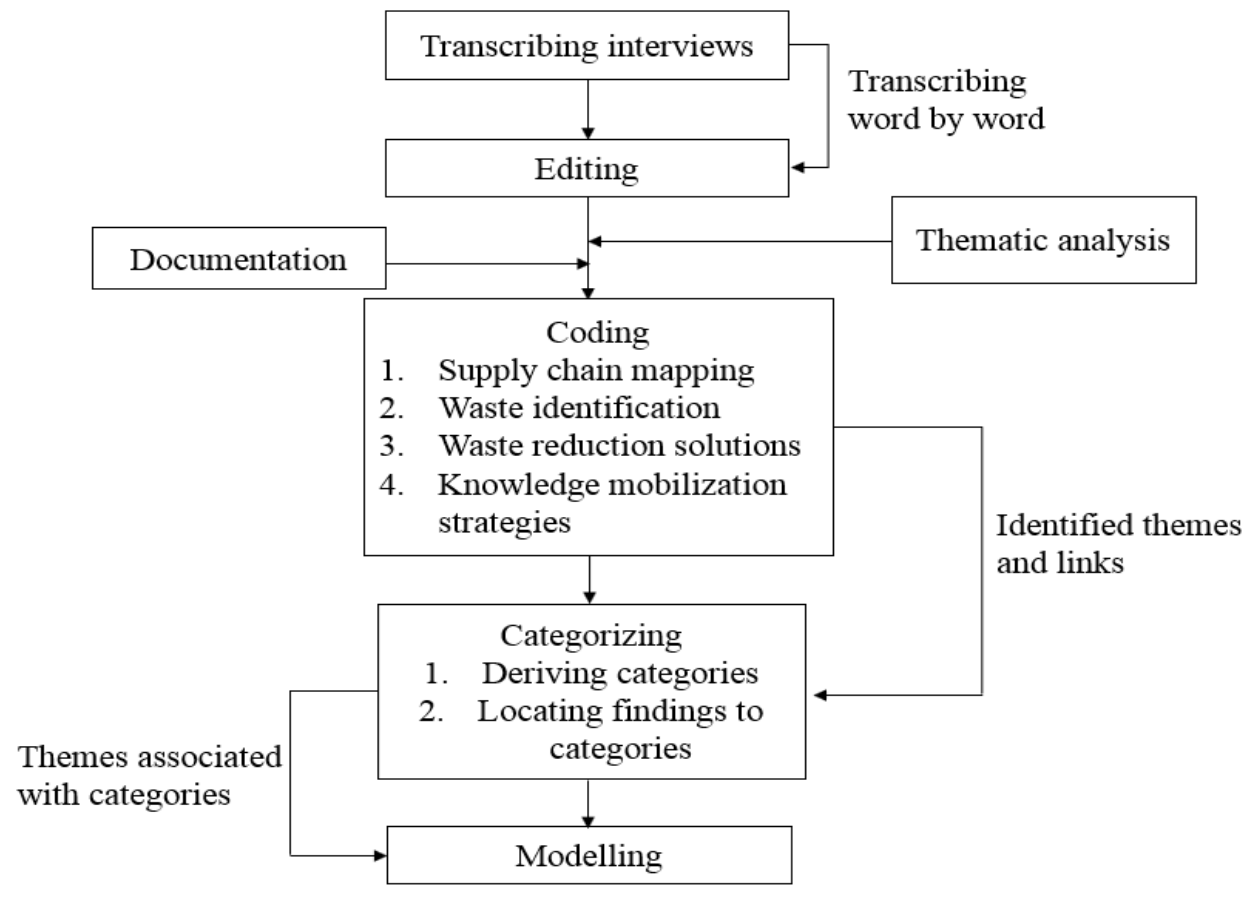

Figure 2: Analysis process

\subsection{Sampling techniques}

This study adopts purposive sampling technique over other techniques available under non-probability sampling method because in purposive sampling, participants are selected based on the research objectives and this ensures adequate representation of important themes. For this reason, it is sometimes known as judgemental sampling. It is often used when working with very small samples such as case study research (Neuman, 2013; Saunders et al., 2009). France is a key player on the market as the world's sixth largest cauliflower producer. Brittany is the highest producer of cauliflower in France. Thus, its choice as a sampling state was appropriate (Breton cauliflower, 2015). Data was collected from chain actors in the Brittany cauliflower sector. Through semi-structured interviews, 9 chain actors were interviewed, which include 3 producers, 1 cooperative, 2 logistics service providers, 1 wholesaler and 2 retailers. The respondents were business owners or company managers who were responsible for major supply chain activities in the companies. Some questions were reworded to improve validity and clarity based on the feedback from the pilot test.

The demographic profile of the participants in the interviews are detailed in the Table 1. The participated CEOs and company managers are all highly educated and experienced.

Table 1: Demographic profile of the respondents

\begin{tabular}{llc}
\hline Types of classification & Category & Number of respondents \\
\hline Gender & Male & 8 \\
& Female & 1 \\
Age & 25-34 years & 1 \\
& 35-44 years & 5 \\
& $45-54$ years & 2
\end{tabular}


Identifying knowledge brokers, artefacts and channels for waste reduction in agri-food supply chains

\begin{tabular}{lll} 
& $55-64$ years & 1 \\
Education & Doctorate & 1 \\
& Master & 3 \\
& Bachelor & 4 \\
Position & High School/Technical training diploma & 1 \\
\multirow{3}{*}{ Work experience } & CEO & 3 \\
& Company manager & 6 \\
& 2-5 years & 1 \\
& 6-10 years & 5 \\
\hline
\end{tabular}

\section{CASE STUDY}

\subsection{Cauliflower supply chain mapping}

Even if China and India share $70 \%$ of the world production, three-quarters of the French production of cauliflower are grown in the North West of France, on the Breton coast. France is the sixth largest producer of cauliflowers in the world (representing $2 \%$ of global production). China comes first with $45 \%$ of global production (the equivalent of 7 million tons), followed by India, Italy, Spain and the United States (Breton cauliflower, 2015). Besides that, $80 \%$ of French production takes place in Brittany, representing around 300,000 tons per year. Brittany is the leading region for cauliflower production in Europe. It contains around 1500 cauliflower producers. $80 \%$ of Breton farms grow cauliflowers, on an average plot of 27 acres. That represents a production surface area of 45,000 acres, or $95 \%$ of the surface area dedicated to cauliflower growing in France (Singh et al., 2018).

The first stage of this study is value chain mapping and identifying the supply chain members for cauliflower. The data were collected from the reports of CERAFEL (Association of Producer Organizations vegetables, fruits and horticulture) and the Chambers of Agriculture of Brittany. The daily operation model is shown at Figure 3. The operations are based on orders: the producer provides products to the cooperative. The retailer places an order with the wholesaler. All products are gathered in the cooperative and are transported via cooperative to the wholesaler and the retailer. In this model, the cooperative takes an important role in managing the supply chain because it is responsible for the vulnerable producer. Moreover, cooperatives increase producer's income in a number of ways. These include: raising the general price level for products marketed or lowering the level for supplies purchased; reducing per-unit handling or processing costs by assembling large volumes, e.g., economies of size or scale; upgrading the quality of supplies or farm products handled (Valentinov, 2007). The model also brings savings and more efficiency into the process. For example, shelf availability has improved a lot. Each day the cooperative checks the remaining shelf life of each product item manually in order to find out the impact of the buffer stock on product freshness. As a result, the remaining shelf life decreased by more than one day, and it increases the risk of products becoming waste. Therefore, there is still room for improvement in balancing availability and lost profit. 


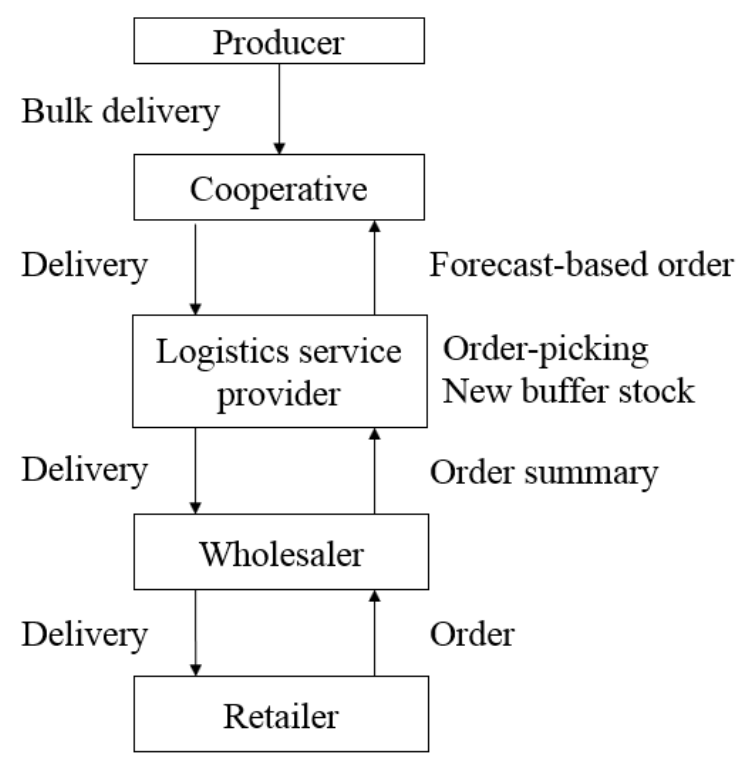

Figure 3: Daily operation model

Since the Brittany cauliflower sector suffered from various problems such as shelf-life management, demand forecast and waste management, several case features have been identified in Table 2.

Table 2: Case features

\begin{tabular}{ll}
\hline Features & Cauliflower \\
\hline Time period studied & One month \\
Product shelf life & $7-21$ days \\
Structure of supply chain & Producer, cooperative, logistics service provider, wholesaler, retailer \\
Main problems & $\begin{array}{l}\text { Inadequate response to demand changes; High inventory levels in } \\
\text { stores; lots of wasted products at the retailer; products reach the store } \\
\text { with a short remaining shelf life, inaccurate ordering }\end{array}$ \\
\hline
\end{tabular}

\subsection{Main findings}

By using the data analysis method detailed in Section 4, this section summaries the main research findings in terms of waste identification, solutions for waste reduction, and knowledge mobilization strategies consists of knowledge brokers, knowledge artefacts and knowledge channels. Firstly, Table 3 presents the main activities undertaken by knowledge brokers for knowledge mobilization. Then Table 4 summaries the links from knowledge brokers, artefacts and channels to reduce relevant types of waste via the case study. On one hand, knowledge artefact and knowledge channel are identified as the main tools of knowledge mobilization. On the other hand, in order to connect networking and communication to support lean, some knowledge mobilization studies have also highlighted the role of knowledge brokering in the agri-food sector. Knowledge brokering contextualizes the knowledge by communicating with farmer groups or producer associations. Furthermore, in linking rural farmers with the national and international researchers, the farmers' community, research institutes or training centers could also develop a self-driven system to manage all crucial issues. In agri-food sector, agricultural authorities are the ones who have 


\section{Identifying knowledge brokers, artefacts and channels for waste reduction in agri-food supply chains}

the whole idea about the agri-food supply chain and have core information about its operations. They have to keep communicating with the farmers and give necessary advice. Acknowledging farmers is the key to streamline the supply chain process where the authorities can create demand driven mindset by providing a sufficient knowledge on consumer requirements, farmer techniques and so forth. In Brittany, there are research and experimentation centers (e.g. CERAFEL-association of producer organization; VEGENOVbiotechnology; OBS-seed selection and product variety; CATE-greenhouse and open field) and training center (e.g. ISFFEL), which are act as the role of knowledge brokers (See table $3)$.

Table 3: Main activities within knowledge broker

\begin{tabular}{|c|l|}
\hline Knowledge broker & \multicolumn{1}{c|}{ Main activities } \\
\hline CERAFEL & $\begin{array}{l}\text { Supportive agricultural policy for food, spices and allied agricultural crops; } \\
\text { stable prices for agricultural products; increase production in selected crops; } \\
\text { customer friendly and result oriented administrative system; investigation on } \\
\text { marketing issues. }\end{array}$ \\
\hline VEGENOV & $\begin{array}{l}\text { Cell biology; genetic fingerprints of plants and their pathogens; crop protection } \\
\text { (stimulation of plant defenses, disinfection of greenhouses and shelters, } \\
\text { products pesticides ...); sensory and nutritional quality of fruits and vegetables; } \\
\text { monitoring, consulting and support of innovation. }\end{array}$ \\
\hline OBS & $\begin{array}{l}\text { Planting breeding; increase yield per plot; introduce resistance and improve } \\
\text { plant efficiency; satisfy specific consumer expectations }\end{array}$ \\
\hline ISFFEL & $\begin{array}{l}\text { Guaranty competitiveness of the products (production costs, commercial } \\
\text { quality); development of sustainable agriculture and food security; work on } \\
\text { diversification and segmentation }\end{array}$ \\
\hline $\begin{array}{l}\text { Collection, analysis and dissemination of market information; analysis on } \\
\text { consumer behavior; conducting surveys to establish benchmark conditions; } \\
\text { researching on problems related to the input supply and support services }\end{array}$ \\
\hline
\end{tabular}

In terms of what knowledge mobilization strategies (knowledge broker, artefact and knowledge channel) can reduce the identified types of waste, the findings are summarized in Table 4.

\begin{tabular}{|c|c|c|c|}
\hline Knowledge broker & Knowledge artefact & Knowledge channel & $\begin{array}{l}\text { Waste identified in } \\
\text { the case study }\end{array}$ \\
\hline $\begin{array}{ll}\text { - } & \text { CERAFEL } \\
\text { - } & \text { VEGENOV } \\
\text { - } & \text { OBS } \\
\text { - } & \text { CATE } \\
\text { - } & \text { ISFFEL }\end{array}$ & $\begin{array}{l}\text { - } \text { Policy } \\
\text { - Operating system } \\
\text { - } \text { Database } \\
\text { - Web portal } \\
\text { - Content- } \\
\text { management-system } \\
\text { - } \text { CMS) platform } \\
\text { - } \text { Recuments } \\
\text { - Protocols }\end{array}$ & $\begin{array}{l}\text { - } \text { IT system (Internet and } \\
\text { - } \text { Intranet) } \\
\text { - } \quad \text { Appraining } \\
\text { - } \quad \text { Community of practice (CoP) } \\
\text { - } \quad \text { Social events (Team building) } \\
\text { - } \quad \text { Personal relationships } \\
\text { - } \quad \text { Discussion board/forum } \\
\text { - Informal communication } \\
\text { channel: meetings, telephone, } \\
\text { video and audio conferences, } \\
\text { voicemail, email etc. }\end{array}$ & $\begin{array}{ll}\text { - } & \text { Overproduction } \\
\text { - } & \text { Inventory } \\
\text { - } & \text { Defects } \\
\text { - } & \text { Transportation } \\
& \text { and motion } \\
\text { - } & \text { Waiting } \\
\text { - } & \text { Over processing }\end{array}$ \\
\hline
\end{tabular}




\section{Table 4: Lean waste and knowledge broker/artefact/channel matrix}

For example, in order to reduce the overproduction waste, adhering to the production schedule which stored in protocols can generate the right amount of output. In addition, the internet has helped chain actors to communicate better and information can be shared over a wide geographical area (Connelly and Kelloway, 2003). The internet also can help chain actors to learn more about the best practices of others, which could save time and money. Therefore, the internet has become a very useful source of information.

In order to reduce the inventory waste, operating system optimization can reduce the level to the minimum. For instance, in Brittany, lacking adequate storage forces producers to deliver all food products to the cooperative, however, in the cooperative, there are evaporative coolers which strictly followed the technological rules to store products. Technological system application is transferred by trainings between experts and grass roots. In Brittany, ISFFEL is a training center which provides training courses in the trades of commerce, distribution, logistics and quality to meet the needs of customer requirements. Through such training, chain actors have a better understanding of the agriculture knowledge and the concept of knowledge mobilization.

In order to reduce the defects waste, quality control which is normally stored in the documents and reports have a positive influence on preventing the obsolete products occurred. Improving standards by documenting them and training operators can reduce the defects waste as well. Then, the community of practice $(\mathrm{CoP})$ has emerged as one of the most widely praised approaches to knowledge mobilization in agri-food sector. CoP are "groups of people who share a concern, a set of problems, or a passion about a topic, and who deepen their knowledge and expertise in this area by interacting on an ongoing basis" (Wenger et al., 2002). CoP provides a platform for innovation among its members. It aims to construct a holistic and inclusive approach to develop actionable knowledge for innovations in agriculture. In terms of quality control, all chain actors are not only trying to complement, encourage discussion to take place within the CoPs, but also trying to bring members to the attention of others when there may be a potential for synergies. CoP members would play a role by interacting voluntarily among each other to find common solutions to problems. Members learn from each other, discuss new ideas, emerging technologies, share resources to improve their skills through collaborative learning (Cox et al., 2008).

\section{CONCLUSIONS}

First, in Brittany cauliflower supply chain, research institutions act as knowledge brokers between the available knowledge system and the individual needs of various chain actors. The technical as well as intellectual capability of development research institutes determines effective mobilization of the agricultural knowledge to chain actors.

Second, two distinct of knowledge communication mechanisms are identified: hard and soft. Hard knowledge transfer mechanisms represent ways of circulating knowledge to develop shared best practice such as knowledge management system (KMS). However, soft knowledge transfer mechanisms foster the social production of new knowledge, allowing actors to adapt and apply their learning about specific skill sets in their own specific cultural and institutional contexts, therefore, communities of practice (COP) seems central to business model improvement.

Our findings also suggest that discarded product is mainly attributed to defects, inventory and overproduction waste categories as described in lean manufacturing. Consequently, this study shows that the lean concept is appropriate for agri-food supply chains. The lean 
production gives methods for a food company to analyze and reduce unnecessary inventories and other forms of waste along the supply chain.

Managerial implications from this study are twofold. First, in the context of agri-food supply chains waste reduction, decision makers' judgements can be significantly improved by using well-developed knowledge mobilization strategies. Managers should encourage to apply knowledge brokers, artefacts and channels within lean supply chain management systems. Second, managers in lean supply chains should think holistically because of the complexity of agri-food supply networks. Sufficient considerations need to be given to decision propagation path on the upstream and downstream supply chain and decision change management (Liu et al., 2013).

Despite this study offers contributions for the development of more mature and reliable knowledge communication channels and mobilization strategies, the agri-food sector can be configured in a variety of different ways. Thereinto, using a clearly defined framework to plan and implement knowledge brokering interventions more consistently would be a significant step towards generating more evidence about the use of brokering in practice. In addition, supply network classification of different food products in different regions need to be further clarified as well. Moreover, this study has limitation that presents opportunities for future research. Different industries may prefer a specific knowledge mobilization strategy in the worldwide marketplace. In this regard, future research should investigate knowledge mobilization in different industries.

\section{REFERENCES}

Alkhuraiji, A., Liu, S., Oderanti, F.O. and Megicks, P., 2016. New structured knowledge network for strategic decision-making in IT innovative and implementable projects. Journal of Business Research, 69(5), pp.1534-1538

Anastasiadis, F. and Poole, N., 2015. Emergent supply chains in the agri-food sector: insights from a whole chain approach. Supply Chain Management: An International Journal, 20(4), pp.353-368.

Attride-Stirling, J., 2001. Thematic networks: an analytic tool for qualitative research. Qualitative research, 1(3), pp.385-405.

Bhamu, J. and Singh Sangwan, K., 2014. Lean manufacturing: literature review and research issues. International Journal of Operations \& Production Management, 34(7), pp.876-940.

Bournaris, T., Moulogianni, C., Arampatzis, S., Kiomourtzi, F., Wascher, D.M. and Manos, B., 2016. A knowledge brokerage approach for assessing the impacts of the setting up young farmers policy measure in Greece. Environmental Impact Assessment Review, 57, pp.159166.

Braun, V. and Clarke, V., 2006. Using thematic analysis in psychology. Qualitative research in psychology, 3(2), pp.77-101.

Breton cauliflower, 2015, France Agroalimentaire, https://www.franceagroalimentaire.com/en/thematiques/data-sheet/articles/data-sheet-on-thebreton-cauliflower/

Carlile, P.R., 2002. A pragmatic view of knowledge and boundaries: Boundary objects in new product development. Organization science, 13(4), pp.442-455.

Carlile, P.R., 2004. Transferring, translating, and transforming: An integrative framework for 
managing knowledge across boundaries. Organization science, 15(5), pp.555-568.

Chen, H., Liu, S. and Oderanti, F., 2017. A knowledge network and mobilisation framework for lean supply chain decisions in agri-food industry. International Journal of Decision Support System Technology (IJDSST), 9(4), pp.37-48.

Cox, A. and Chicksand, D., 2008. Rethinking policy options for industry: appropriateness in policies for industry and UK farming and food. Public Administration, 86(3), pp.813-836.

Cox, R., Holloway, L., Venn, L., Dowler, L., Hein, J.R., Kneafsey, M. and Tuomainen, H., 2008. Common ground? Motivations for participation in a community-supported agriculture scheme. Local environment, 13(3), pp.203-218.

Connelly, C.E. and Kevin Kelloway, E., 2003. Predictors of employees' perceptions of knowledge sharing cultures. Leadership \& Organization Development Journal, 24(5), pp.294-301.

De Steur, H., Wesana, J., Dora, M.K., Pearce, D. and Gellynck, X., 2016. Applying value stream mapping to reduce food losses and wastes in supply chains: A systematic review. Waste management, 58, pp.359-368.

Dora, M., Van Goubergen, D., Kumar, M., Molnar, A. and Gellynck, X., 2014. Application of lean practices in small and medium-sized food enterprises. British Food Journal, 116(1), pp.125-141.

Dora, M., Kumar, M. and Gellynck, X., 2016. Determinants and barriers to lean implementation in food-processing SMEs-a multiple case analysis. Production Planning \& Control, 27(1), pp.1-23.

Hansen, M.T. and Haas, M.R., 2001. Competing for attention in knowledge markets: Electronic document dissemination in a management consulting company. Administrative Science Quarterly, 46(1), pp.1-28.

Hartwich, F., Monge Pérez, M., Ampuero Ramos, L. and Soto, J.L., 2007. Knowledge management for agricultural innovation: Lessons from networking efforts in the Bolivian Agricultural Technology System. Knowledge Management for Development Journal, 3(2), pp.21-37.

Heymans, B., 2015. Lean manufacturing and the food industry. Journal of Technology Management \& Innovation, 10(3), pp.120-30.

Holford, W.D., 2016. Boundary constructions as knowledge flows within and between work groups. Knowledge Management Research \& Practice, 14(1), pp.4-14.

Hustad, E., 2007. Managing Structural Diversity: the Case of Boundary Spanning Networks. Electronic Journal of Knowledge Management, 5(4).

Hutchinson, V. and Quintas, P., 2008. Do SMEs do knowledge management? Or simply manage what they know?. International Small Business Journal, 26(2), pp.131-154.

Islam, F., 2015. Institutionalization of agricultural knowledge management system for digital marginalized brural farming community.

Jacobson, N., Butterill, D. and Goering, P., 2005. Consulting as a strategy for knowledge transfer. The Milbank Quarterly, 83(2), pp.299-321.

Kajamaa, A., 2011. Boundary breaking in a hospital: expansive learning between the worlds 
Identifying knowledge brokers, artefacts and channels for waste reduction in agri-food supply chains

of evaluation and frontline work. The Learning Organization, 18(5), pp.361-377.

Kellogg, K.C., Orlikowski, W.J. and Yates, J., 2006. Life in the trading zone: Structuring coordination across boundaries in postbureaucratic organizations. Organization science, $17(1), \mathrm{pp} .22-44$.

King, N. and Horrocks, C., 2010. Interviews in qualitative research. Sage.

Kislov, R., Harvey, G. and Walshe, K., 2011. Collaborations for Leadership in Applied Health Research and Care: lessons from the theory of communities of practice. Implementation Science, 6(1), p.64.

Kittipanya-ngam, P., Shi, Y. and Gregory, M.J., 2010. Food supply chain (FSC) in manufacturing companies-an exploratory study on product and configuration. In Proceedings of 17th EurOMA Conference, Porto, Portugal.

Liker, J.K., 2005. The toyota way. Esensi.

Liu, S., Leat, M., Moizer, J., Megicks, P. and Kasturiratne, D., 2013. A decision-focused knowledge management framework to support collaborative decision making for lean supply chain management. International Journal of Production Research, 51(7), pp.2123-2137.

Maaninen-Olsson, E., Wismén, M. and Carlsson, S.A., 2008. Permanent and temporary work practices: knowledge integration and the meaning of boundary activities. Knowledge Management Research \& Practice, 6(4), pp.260-273.

Mariano, S. and Awazu, Y., 2016. Artifacts in knowledge management research: a systematic literature review and future research directions. Journal of Knowledge Management, 20(6), pp.1333-1352.

Mason, K.J. and Leek, S., 2008. Learning to build a supply network: an exploration of dynamic business models. Journal of Management Studies, 45(4), pp.774-799.

Meyer, M., 2010. The rise of the knowledge broker. Science communication, 32(1), pp.118127.

Morse, J.M., 2003. Principles of mixed methods and multimethod research design. Handbook of mixed methods in social and behavioral research, 1, pp.189-208.

Neuman, W.L., 2013. Social research methods: Qualitative and quantitative approaches. Pearson education.

Ohno, T., 1988. Toyota production system: beyond large-scale production. crc Press.

Rogers, E.M., 2010. Diffusion of innovations. Simon and Schuster.

Saunders, M., Lewis, P. and Thornhill, A., 2009. Research methods for business students. Pearson education.

Semeon, G., Garfield, M.J., Meshesha, M. and David, D., 2013. Agricultural Knowledge Management Systems in Practice: The Ability to Support Wereda Knowledge Centers in Ethiopia.

Shingo, S. and Dillon, A.P., 1989. A study of the Toyota production system: From an Industrial Engineering Viewpoint. CRC Press.

Singh, B.K., Singh, B. and Singh, P.M., 2018. Breeding Cauliflower: A

Review. International Journal of Vegetable Science, 24(1), pp.58-84. 
Szulanski, G., 1996. Exploring internal stickiness: Impediments to the transfer of best practice within the firm. Strategic management journal, 17(S2), pp.27-43.

Taylor, D.H., 2005. Value chain analysis: an approach to supply chain improvement in agrifood chains. International Journal of Physical Distribution \& Logistics Management, 35(10), pp.744-761.

Valentinov, V., 2007. Why are cooperatives important in agriculture? An organizational economics perspective. Journal of institutional Economics, 3(1), pp.55-69.

Vamsi Krishna Jasti, N. and Kodali, R., 2014. A literature review of empirical research methodology in lean manufacturing. International Journal of Operations \& Production Management, 34(8), pp.1080-1122.

Ward, V., House, A. and Hamer, S., 2009. Knowledge brokering: the missing link in the evidence to action chain?. Evidence \& policy: a journal of research, debate and practice, 5(3), pp.267-279.

Wenger, E., 1999. Communities of practice: Learning, meaning, and identity. Cambridge university press.

Wenger, E., 2000. Communities of practice and social learning systems. Organization, 7(2), pp.225-246.

Wenger, E., McDermott, R.A. and Snyder, W., 2002. Cultivating communities of practice: A guide to managing knowledge. Harvard Business Press.

Womack, J.P., Womack, J.P., Jones, D.T. and Roos, D., 1990. Machine that changed the world. Simon and Schuster.

Womack, J.P. and Jones, D.T., 1997. Lean thinking-banish waste and create wealth in your corporation. Journal of the Operational Research Society, 48(11), pp.1148-1148.

Zuo, Y. and Panda, B., 2013. Composition and combination-based object trust evaluation for knowledge management in virtual organizations. VINE, 43(3), pp.296-321. 